\section{Effect of Season on Internet Searches for Information on Raynaud Phenomenon}

\section{To the Editor:}

I read with great interest the recent article by Pauling, et $a l^{1}$, which examined factors influencing Raynaud condition score (RCS) diary outcomes in systemic sclerosis (SSc). Patients with SSc were recruited at sites in both the United Kingdom and the United States and completed the RCS at both baseline and 6 months. The authors report significant associations between RCS diary outcomes and both environmental temperature and season of enrollment. Both have significant implications for future clinical trial design, including to establish efficacy of much-needed treatments for Raynaud phenomenon $(\mathrm{RP})^{2,3}$. Despite a wide range of available drug therapies for $\mathrm{RP}$ including SSc-RP $\mathrm{P}^{4,5}$, these are seldom fully effective ${ }^{6}$. Patients are increasingly using mobile health technology to learn more about symptoms and conditions/treatments ${ }^{7}$, and these data can also provide novel insights into the patient experience of disease. Zhao, et $a l^{8}$ recently demonstrated that there are clear seasonal variations (greatest in the summer months) in Internet search volumes for key phrases associated with joint swelling.

Against this background, publicly available data from Google Trends were examined (run in the "Health" category) for "Raynaud's" to look for evidence of seasonal variations in RP. Data are presented for the United Kingdom (Figure 1A), United States (Figure 1B), and worldwide (Figure 1C). Searches were run from 2004 to April 22, 2019. Data are presented as "interest over time" (Y axis), in which 100 is the peak popularity for the term and 50 is half as popular (a score of 0 is assigned with insufficient data). Date (month and year) data are presented on the $\mathrm{X}$ axis. Significant peaks and troughs are annotated (month and year) on Figure 1A to orient the reader.
There was clear evidence of trends in online searches for RP, which were greatest in the winter months and lowest in the summer months for the UK, US, and worldwide. These data further confirm the marked seasonality of Raynaud symptoms ${ }^{9}$. Therefore, it could be desirable in future studies of RP to test new treatments during the colder months when RP symptoms are most severe ${ }^{2}$. Further, studies should also be of short duration to minimize the effect of change in season/weather on RP. Future clinical trials of RP must strongly consider the effect of the seasonal variation of the weather in their study design, including the need to incorporate novel methods of assessment (e.g., patient-reported outcome measures and microvascular imaging techniques).

MICHAEL HUGHES (1), PhD, BSc (Hons), MSc, MBBS, MRCP (UK) (Rheumatology), Department of Rheumatology, Royal Hallamshire Hospital, Sheffield Teaching Hospitals NHS Foundation Trust, Sheffield, UK. Address correspondence to Dr. M. Hughes, Department of Rheumatology, Royal Hallamshire Hospital, Sheffield Teaching Hospitals NHS Foundation Trust, Sheffield, S10 2JF, UK.

E-mail: Michael.Hughes-6@postgrad.manchester.ac.uk.

\section{REFERENCES}

1. Pauling JD, Reilly E, Smith T, Frech TM. Factors influencing Raynaud condition score diary outcomes in systemic sclerosis. J Rheumatol 2019 May 15 (E-pub ahead of print).

2. Pauling JD. The challenge of establishing treatment efficacy for cutaneous vascular manifestations of systemic sclerosis. Expert Rev Clin Immunol 2018;14:431-42.

3. Pauling JD, Nagaraja V, Khanna D. Insight into the contrasting findings of therapeutic trials of digital ischaemic manifestations of

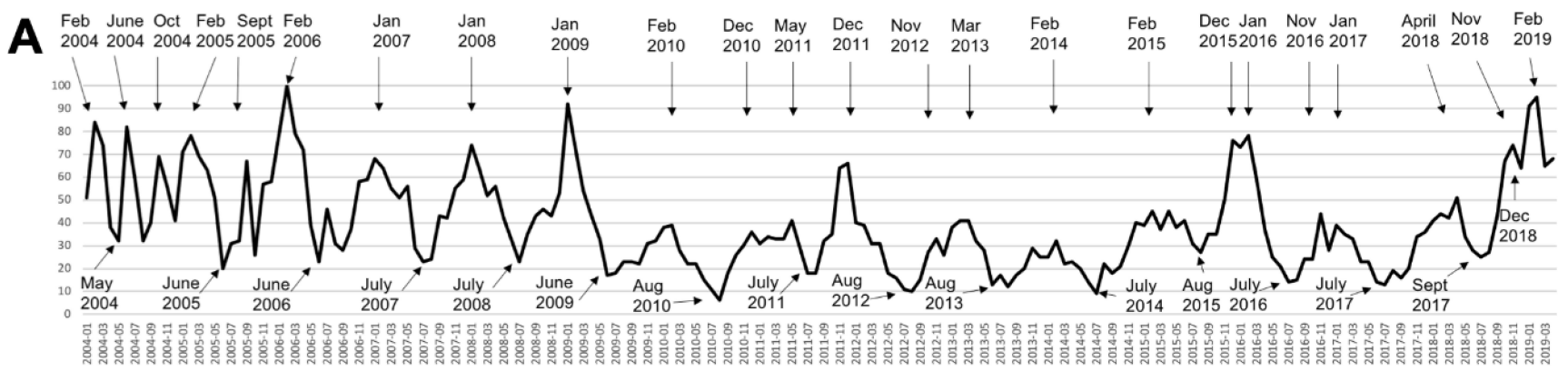

\title{
B
}

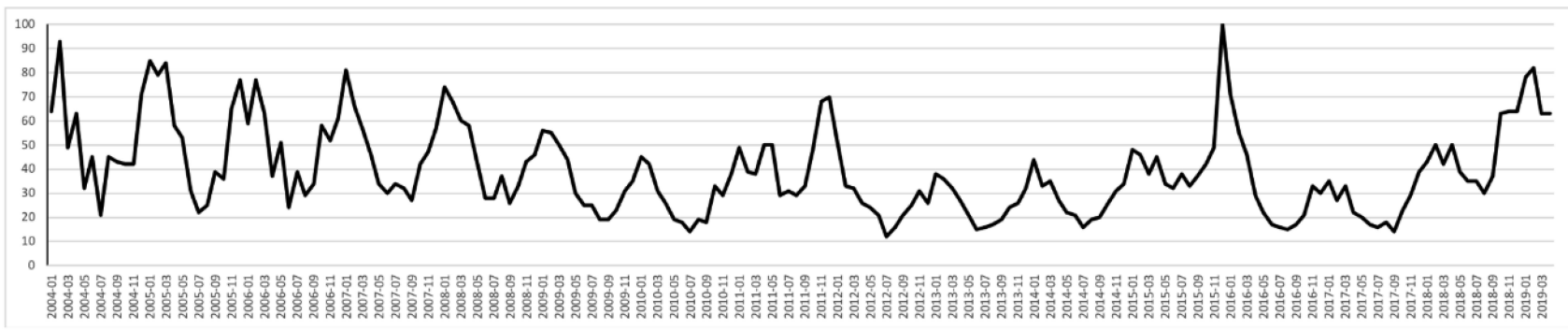

C

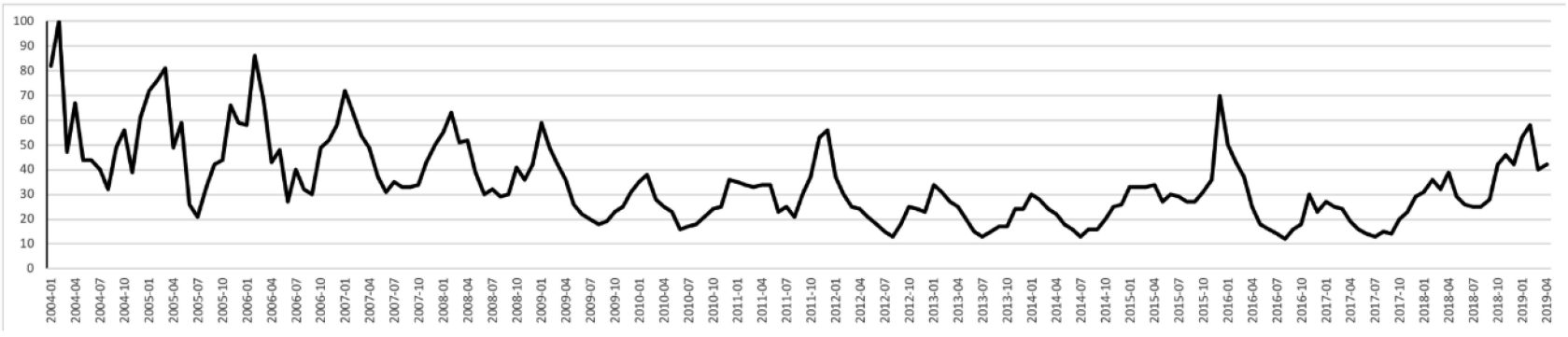

Figure 1. Seasonal variation in Internet searches for information on Raynaud phenomenon in the United Kingdom (A), United States (B), and worldwide (C). 
systemic sclerosis. Curr Treatm Opt Rheumatol 2019;5:85-103.

4. Hughes M, Ong VH, Anderson ME, Hall F, Moinzadeh P, Griffiths $\mathrm{B}$, et al. Consensus best practice pathway of the UK Scleroderma Study Group: digital vasculopathy in systemic sclerosis.

Rheumatology 2015;54:2015-24.

5. Denton CP, Hughes M, Gak N, Vila J, Buch MH, Chakravarty K, et al. BSR and BHPR guideline for the treatment of systemic sclerosis. Rheumatology 2016;55:1906-10.

6. Hughes M, Snapir A, Wilkinson J, Snapir D, Wigley FM, Herrick AL. Prediction and impact of attacks of Raynaud's phenomenon, as judged by patient perception. Rheumatology 2015;54:1443-7.

7. Hughes M, Baker A, Farrington S, Pauling JD. Patient organisation-led initiatives can play an important role in raising awareness about Raynaud's phenomenon and encourage earlier healthcare utilisation for high-risk groups. Ann Rheum Dis 2019;78:439-41.

8. Zhao S, Duffield S, Hughes DM. Seasonal variations of Google searches for joint swelling: implications for patient-reported outcomes. Clin Rheumatol 2019;38:1791-2.

9. Watson HR, Robb R, Belcher G, Belch JJ. Seasonal variation of Raynaud's phenomenon secondary to systemic sclerosis. J Rheumatol 1999;26:1734-7.

First Release July 15 2019; J Rheumatol 2019;46:11; doi:10.3899/jrheum.190463 